\title{
¿Ética en Heidegger? Una pregunta inquietante
}

\author{
Juan Manuel Silva Camarena
}

E

126 de septiembre de 1946 Martín Heidegger cumplió 57 años. Sin lugar a dudas el año de 1946 fue uno de los más difíciles de su vida, por lo sombrío de sus estaciones: la primavera del derrumbe, el verano de las humillaciones y el otoño de la penuria material y las decepciones. En efecto, en la primavera de ese año, él estuvo en un tratamiento psicosomático en el sanatorio Schloss Haus Baden, en Badenweiler, bajo la atención del psiquiatra Viktor von Gebsattel, pues ante los ataques y la imputación de cargos de la época de su rectorado, "se había derrumbado física y moralmente". ${ }^{1}$ Heidegger sostuvo siempre que ese pasado político "fue algo bien diferente a una adhesión al partido y a su doctrina". ${ }^{2}$ Por esa razón, durante el verano "se sintió malentendido, perseguido y difamado" injustamente, ya que tuvo que sufrir las humillaciones que para él tomaron cuerpo tanto en la confiscación parcial de su casa y la inminente confiscación de su biblioteca, como en el castigo de participar obligadamente en las tareas de desescombramiento de las calles de Friburgo. ${ }^{3}$ Finalmente, en el otoño del mismo año, entre serias dificultades económicas ${ }^{4}$ y malos presentimientos recibió el duro golpe del veredicto definitivo del gobierno militar francés: "Il est interdit a M. Heidegger d'enseigner et de participer à tout activité de la l'Université". El Ministerio de Cultura de Baden le informó su destitución:

En el marco de la depuración política de la administración, el 28 de diciembre de 1946 ha sido tomada la siguiente decisión: prohibición do-

${ }^{1}$ Hugo Ott, Heidegger. En camino hacia su biografía. Trad. de Helena Cortés Gabaudan. Madrid, Alianza, 1992, p. 357.

${ }^{2}$ Ibid., p. 25.

${ }^{3}$ Cf. ibid., p. 361.

${ }^{4}$ Cf. ibid., p. 132. 
cente y ninguna función dentro de la universidad. La prohibición docente entra en función de inmediato. El abono de su sueldo cesará a finales de 1947.5

No había vuelta de hoja. Estas estaciones del desprestigio y la inculpación tuvieron que provocar en su ánimo la experiencia de la amargura y la desmoralización.

El veredicto de la separación de su cargo universitario fue dictado provisionalmente el 5 de octubre, nueve días antes de su cumpleaños. A menos de un mes, el 10 de noviembre, Jean Beaufret escribió a Heidegger una carta en la que le planteaba tres cuestiones filosóficas: una de ellas relacionada con el humanismo, otra que tenía que ver con la ética y la ontología, y una más en relación con la idea de la filosofía como aventura. Heidegger tomó en serio las preguntas de quien con el paso del tiempo sería el famoso interlocutor francés del filósofo alemán de la Selva Negra, y redactó un texto que fue enviado a su destinatario en el mes de diciembre del mismo año, y que todos conocemos con el nombre de Carta sobre el humanismo. ${ }^{6}$ Este escrito, ampliado y revisado por su autor, se publicó en 1947.

La vinculación que pueda establecerse entre pensamiento y vida no debe prestarse a ninguna tosca manipulación de los que creen en la filosofía como mera expresión de circunstancias. Pero si consideramos a Heidegger simplemente como un pensador que nació, vivió y murió, y que lo que esto implica no tuvo nada que ver con los trazos de su pensamiento, estamos seguros que algo no quedaría bien comprendido del todo. Para decirlo sin ambicionar tanto como la comprensión, algo, por lo menos algo se escaparía de ser siquiera mirado. Por ejemplo, no tendríamos ojos para advertir, en la expresión de una de esas paradojas que la vida suele plantearnos como si quisiera mostrar la impotencia de nuestras más finas y agudas capacidades de comprensión, que unos franceses (como los del gobierno militar de ocupación establecido en Friburgo) condenaban a Heidegger, mientras que al mismo tiempo otros franceses (como los que eran representados por Jean Beaufret) lo salvaban. ¿Y cómo lo salvaban? Sencillamente pidiendo a Heidegger que, como ave fénix ${ }^{7}$ como en un renacimiento de las cenizas que quedaron de la hoguera de la primavera, el verano y el otoño de 1946, tomara la palabra para determinar y estimular el pensamiento filosófico y la actitud de los jóvenes en lo relativo

${ }^{5}$ Ibid., p. 359.

${ }^{6}$ La edición a que hacemos referencia es Martin Heidegger, Lettre Sur L'Humanisme. Trad. y presentación de Roger Munier. París, Aubier, Montaigne, 1964.

${ }^{7}$ Para emplear la metáfora que usa Ott (cf. H. Ott, op. cit., p. 359). 
a las cosas del espíritu. ${ }^{8}$ Da lo mismo si el pedido era para Francia o Alemania, para América o la Unión Soviética.

Ahora bien: ¿cuáles eran las cosas del espíritu que en esa época parecía necesario atender con mayor urgencia con la lucidez del pensamiento filosófico? A juzgar por las preguntas del filósofo francés, se trataba de las mismas cosas que inquietan nuestro espíritu hoy, aquí, poco más de cincuenta años más tarde. Efectivamente, a nosotros, como a Heidegger, alguien puede preguntarnos cuándo escribimos una ética. No queremos insinuar, claro está, que tengamos los mismos recursos que él. Sólo afirmamos que tenemos planteada la misma exigencia, aunque a nuestra vida le pasen cosas distintas.

Las preguntas de Beaufret eran éstas: en primer lugar, la de la posibilidad de restablecer el sentido de la palabra humanismo; en segundo, la que se refiere a la relación entre la ontología y la ética, y finalmente, la que interroga por el modo en que se puede conservar el sentido de aventura de la filosofía sin convertirla en una "simple aventurera". Las respuestas de Heidegger, desarrolladas en muchas páginas, son, en verdad, muy sencillas; y al mismo tiempo, muy complicadas. Ciertamente reducidas con rudeza a una mínima expresión, sus respuestas hablan de lo siguiente: ¿podemos seguir siendo humanistas hoy? En modo alguno. El humanismo es metafísica, y la metafísica debe terminar para que podamos ser lo que nos corresponde ser en relación con el ser. ¿Hay la posibilidad de un verdadero humanismo? Sí, el de la defensa del hombre, que defiende su esencia, o sea, su pertenencia al ser. ¿Es importante precisar la relación entre ética y ontología? En modo alguno. Porque la filosofía como verdadero pensar no es ni ética ni ontología. Pero de la filosofía, como pensamiento teórico de la verdad del ser y su posesión del hombre, ¿se puede derivar indicaciones para la vida? En modo alguno. La filosofía no es ni teórica ni práctica, ella supera toda teoría y toda praxis. La filosofía, como pensar de la verdad del ser, ¿es una mera aventura, y como tal algo arbitrario? En modo alguno. La ley de la que depende es el ser, y éste requiere al pensar a la vez que a él queda destinado.

Al tratar de precisar lo que podría ser la idea central de la Carta sobre el humanismo, aparece una idea por entero sencilla, tan sencilla que contrasta fuertemente con la proverbial dificultad para estudiar a Heidegger: o la filosofía es imposible, y jamás podremos pensar al hombre en su peculiar relación con el ser, o ella es posible y lo que se ha hecho hasta ahora bajo este nombre (es decir, pensar al ser humano y al ser fuera de su relación recíproca), no es realmente filosofía.

Ahora bien, de acuerdo a lo anterior ela ética que se ha hecho hasta ahora no es ética? Sí lo es, pero siéndolo, no es filosofía, o si se quiere, es sólo

${ }^{8}$ Cf. ibid., p. 28. 
"filosofía" (ya sea como metafísica, en el caso de Platón; ya sea como algo independiente de ella, como en el de Aristóteles). Como mera disciplina filosófica, dice Heidegger en la Carta, la ética pertenece y aparece por primera vez en la escuela de Platón, cuando el pensamiento se marchita precisamente porque se vuelve "filosofía", y ésta se convierte en ciencia. Antes de esa época, los pensadores no conocen la "lógica" ni la "ética", pero su pensamiento no es ni ilógico ni inmoral: Dennoch ist ihr Denken weder unlogish, noch unmoralisch ${ }^{9}$ Esto quiere decir, a nuestro juicio, que el pensamiento que no se ha vuelto "filosofía" o el que quiere dejar de serlo piensa la moral (como lo hace Heidegger en $\mathrm{El}$ ser y el tiempo, manteniendo una distinción entre la conciencia vulgar y la conciencia auténtica), pero no se convierte en ética. La otra cosa que se puede hacer, en lugar de hacer ética, es pensar la moral, y esto no puede consistir en dar indicaciones o máximas, que precisamente rehusarían a la conciencia moral la posibilidad de obrar, ${ }^{10}$ sino despertar en nosotros la disposición para escuchar otras indicaciones.

Es cierto que para Heidegger en la dimensión del trabajo del pensamiento auténtico, de acuerdo a la significación fundamental de la palabra ethos, la ontología es la ética original porque ésta es ontología. ${ }^{11}$ Pero esta ética no es la ética de la "filosofía", y esta ontología tampoco es la ontología de la "filosofía". No debemos perder de vista que para él las tragedias de Sófocles "entrañan en su decir el ethos" más primariamente que las lecciones de Aristóteles sobre la "ética". ${ }^{12}$ Ese pensar sin ética, es más aclarador del ethos que toda ética, como en el caso del fragmento 119 de Heráclito, que en la lectura de Heidegger dice: "el hombre mora, por cuanto que él es hombre, en la cercanía de Dios". ${ }^{13}$ Con un pensamiento de este tipo, tenemos que dejar de pensar en la moral como una forma de comportamiento que se prepara, se realiza y se juzga según reglas.

Todos sabemos que Jean Paul Sartre termina El ser y la nada (1943) reconociendo que de los indicativos de la ontología no se pueden extraer impera-

${ }^{9}$ Cf. ibid., p. 142.

${ }^{10}$ Cf. M. Heidegger, Sein und Zeit. Tübingen, Max Niemeyer, 1977, parágrafo 59, p. 294 (versión castellana: El ser y el tiempo. Trad. de José Gaos. México, FCE, 1971, parágrafo 59, p. 320).

11 "Así pues, si de acuerdo con la significación fundamental de la palabra ethos, el término ética debe indicar que ella piensa la estancia del hombre, entonces se puede decir que el pensamiento que piensa la verdad del ser como elemento originario del hombre en tanto ec-sistente, es ya en sí misma la ética original. Sin embargo, ese pensar no es ética sino por el hecho de que es ontología" (M. Heidegger, Carta sobre el humanismo, p. 150).

${ }^{12}$ H. Ott, op. cit., pp. 142-144.

${ }^{13}$ Ibid., p. 144. 
tivos o prescripciones morales. Sin embargo, él cree que la ontología deja entrever (entrevoir) lo que sería una ética "que tome sus responsabilidades frente a una realidad humana en situación". ${ }^{14}$ Quizá con un razonamiento semejante al de Sartre, el joven amigo que menciona Heidegger en la Carta, ante la culminación de El ser y el tiempo (1927) se atreve a plantearle directamente la pregunta: “¿Cuándo escribe usted una ética?”. ${ }^{15}$ Y bien: ¿cuál es el fundamento de este atrevimiento? Consideramos que para Heidegger el atrevimiento es la filosofía misma, y se origina al colocar exclusivamente al hombre como horizonte del pensar. Por tanto, hay que poner al hombre en su lugar. Heidegger dice que no estamos en un plan où il y a seulmente des hommes (donde haya solamente hombres, como sostiene Sartre en $E l$ existencialismo es un humanismo), sino en un plan où ily a principalement l'Etre, en el que principalmente hay ser. ${ }^{16}$ Ésta es la gran diferencia.

Principalmente hay ser. ¿Y esto qué significa para la cuestión que nos ocupa? Que no hay ética, donde hay verdadero pensamiento. No sólo porque no puedan derivarse prescripciones morales del pensamiento que se ocupa de lo que es, sino porque las indicaciones para nuestro ser vienen de otro lado. Desde que creemos que somos la medida de todas las cosas (digámoslo o no, seamos conscientes de ello o no), también nos consideramos la medida del bien y el mal. ¿La ética no viene a ser, acaso, algo así como la medida del bien y el mal? Heidegger insiste en que el hombre no es el dueño y señor del ser, sino su pastor, y como tal, en su cuidado, debe oír sus indicaciones. El ser indica, no el hombre.

Hoy la estamos pasando mal. Tal vez hablamos de la misma confusión del ser humano que menciona Heidegger en su Carta: "El deseo de una ética llama tanto más imperiosamente su realización cuanto que la perplejidad (Ratlosigkeit) de los hombres, la que está a la vista y la que está oculta, crece hasta lo inconmensurable". ${ }^{17}$ Como están las cosas (y con esta frase nos queremos referir a todo lo que lamentablemente tenemos ante nuestros ojos), y suponiendo que están como están por falta de ética, ¿quién podría evitar la tentación de creer que lo más urgente es escribir una ética a la altura de las circunstancias? He aquí una pregunta inquietante: ¿cuándo escribimos una ética?

${ }^{14}$ Jean-Paul Sartre, L'Etre et le Néant. Essai d'ontologie phénoménologique. París, Gallimard, 1943, Conclusión, II, p. 690 (J.-P. Sartre, El ser y la nada. Ensayo de ontología fenomenológica. Trad. de Juan Valmar. Buenos Aires, Losada, 1972, conclusión, II, p. 757).

${ }^{15}$ H. Ott, op. cit., pp. 138-140.

16 Ibid., p. 86.

${ }^{17}$ Ibid., p. 140. 
Pero ¿qué se le pide a la filosofía cuando se le solicita una ética? Con esta interrogación se despierta inevitablemente la idea de que el hombre que se considera a sí mismo como "animal racional" estima que su razón es lo más preciado que posee, porque con ella puede saberlo todo (desde cómo desarmar una bicicleta rápidamente, hasta cómo conquistar el espacio sideral en pocos viajes), y con un exceso de sentido común opina que si la razón contiene los secretos del saber, la filosofía, que guarda los secretos de la razón, puede y debe otorgarle una ética para saber qué hacer prácticamente con las cosas de la vida. Por supuesto, nosotros pensamos que ser dueños de nuestro destino no es algo que pueda ponerse en estos términos tan carentes de lucidez o tan sobrados de insensatez.

En las líneas finales de la Carta, Heidegger nos invita a no sobrevalorar más a la filosofía y de este modo dejar de exigirle demasiado: "En la actual penuria del mundo (dice que) es necesario que haya menos filosofia, pero más solícita atención al pensar; menos literatura, pero más cuidado de las letras". ${ }^{18}$ Creemos que podemos agregar: menos ética y más miramiento y esmero en nuestra moral. Así también podríamos exigir menos a la ética y más a nosotros mismos.

${ }^{18}$ Ibid., p. 170. 